\title{
Covid-19 Pandemic: What are the Challenges and Opportunities for e- Leadership?
}

\author{
Duta MUSTAJAB ${ }^{1}$, Azies BAUW', Andri IRAWAN ${ }^{3}$, Abdul RASYID ${ }^{4}$, Mohammad Aldrin \\ AKBAR ${ }^{5}$, Muhammad Amin HAMID
}

ARTICLE INFO

Article History:

Date Submitted: 17.04.2020

Date Accepted: 11.05.2020

JEL Classification:

A20,

M15,

M21.

Keywords:

COVID-19 Pandemic,

e-Leadership,

Small and Medium

Enterprises.

\begin{abstract}
COVID-19 pandemic has surprised many organizations, this condition has an impact on changing the work culture of organizations. The role of information technology has proven to be the chosen solution for maintaining organizational performance. The main objective of this study is to explore the challenges and opportunities for e-leadership. The main focus of the study is directed at educational organizations and small and medium enterprises in Indonesia. A qualitative approach is used to interview informants scattered in several regions in Indonesia by information technology mediation. An important finding in this paper is that many organizations are not ready to face this condition so that the role of e-leadership is very effective for organizations to maintain the organizations performance and leaders can change their leadership style through social learning and overcome the challenges they must face to become e-leader. In addition, we also find that female leaders tend to be superior to men as e-leader, especially in terms of information technology skills and the use of social media. This paper concludes that e-leadership can be created by leaders who can overcome challenges and seize opportunities to build competitive advantage strategies.
\end{abstract}

\footnotetext{
${ }^{1}$ Dr. University of Yapis Papua, Indonesia, duta.mustajab@yahoo.com

${ }^{2}$ Dr., University of Yapis Papua, Indonesia, azies.bauw@yahoo.com

${ }^{3}$ Dr., University of Yapis Papua, Indonesia, andriirawan@ uniyap.ac.id

${ }^{4}$ University of Yapis Papua, Indonesia, abdulrasyid_uniyap@yahoo.com

${ }^{5}$ University of Yapis Papua, Indonesia, aldrinakbar160@gmail.com

${ }^{6}$ University of Yapis Papua, Indonesia, aminuniyap11@gmail.com
} 


\section{Introduction}

Currently, the world is being shocked by the COVID-19 attack, this has explicitly had a very broad impact and posed a firm threat to many aspects such as health, economy, politics, and security. In the health aspect, WHO has established the status that COVID-19 is a pandemic that has attacked almost all countries in the world. In the economic aspect, it has caused many losses due to the cessation of production, sales and many organizations that make temporary layoffs of their employees. Furthermore, COVID-19 has also changed the organization's performance such as working from home (WFH) instructions for employees, virtual organization control and supervision conducted by leaders which previously are only carried out by large organizations such as Google and Microsoft. However, this condition is shock therapy for many organizations in Indonesia and is a valuable lesson to develop competitive advantage strategies and be able to predict the possibility of threats that occur in the future. However, greater investment is needed to deal with this virus, especially investment in the health sector, although other impacts will be affected, such as the global economy and this virus is dangerous for all socio-economic classes, (McKibben \& Fernando, 2020). Besides, at present, many countries are locking up permanently with the term "LockDown" even though it is seen as not the only way and can have an extremely fatal economic and social impact, see (Cruz, 2020), although they consider that there are many ways to restore the economy, yet there are few ways to restore health and protect the lives of the citizens. Thus, once again, it is very important to strengthen funding and investment in health in very unusual conditions today and conduct evidence-based studies that will contribute to economic and health improvements, (Rodela, Tasnim, Mazumber, \& Faizah, 2020).

Effective leadership is that the leaders must have a high spirit that exceeds the enthusiasm of their employees so that trust is very strong to run the leadership and has a clear goal to welcome toward the future. However, of course, it is not easy to carry out effective leadership, especially in these times, leaders must follow the modern era, for example: in this modern era, technology has evolved and a leader must master information and communication technology to apply it to his/her employees. E-Leadership is a term that juxtaposes "e" as a symbol for matters relating to electronics, the internet, or the digital world with "leadership" which means a person's ability to move or influence the people he/she leads for achieving 
organizational goals. E-Leadership is leadership that combines the concepts that already exist today, namely leadership with technological development. Furthermore, the question arises about what are the challenges and opportunities for organizational leaders in managing their organizations during the COVID-19 pandemic? Limitation of social activities and instructions for doing work from home will certainly have an impact on organizational performance and leadership. As such, it is necessary to explore how organizational leaders face these challenges and how they are able to create opportunities for organizational development and leadership during the COVID-19 pandemic? This is interesting to be explored in more depth and certainly will contribute to leadership theories and as a reference for future research related to research on leadership and e-leadership.

\section{Literature Review}

The role of e-leadership in the current revolution era is no longer a necessity but it is an obligation for large or small and medium organizations to maintain the existence and performance of the organizations to be able to survive and compete with business competitors and non-competing threats such as natural disasters, wars and extraordinary events that can stop organization's performance so that organizations need leaders who have the ambition to open opportunities offered by digital technology and can ensure fair, solid, and ecological development at the global level as a way to prevent and fight social and economic disasters that occur at this time or in the future, (Capogna, Figus, \& Mustica, 2018). Theories and concepts about the current leadership style continue to develop, this is because-leadership is an interesting problem for many researchers as a study topic and starting from 1990 to 2019, there have been many studies on leadership that contribute both practically and theoretically to the development of concepts and theories, this includes e-leadership (Rey-Martí, Ribeiro-Soriano, \& Sánchez-García, 2016). However, currently, studies on each e-leadership are considered lacking, especially those that highlight issues of leadership style, challenges, culture, training, and development as well as guidelines as leaders who must transform in the current digital era, see (Oh \& Chua, 2018), although today, some still think that e-leadership is a combination of traditional communication with information technology, (Van Wart, Roman, Wang, \& Liu, 2019). Furthermore, a good leader is certainly someone who is able to develop competitive advantage strategies and influence everyone in the organization through his/her ability, both 
management and spiritual skills, to continue to improve the organization's performance, regardless of whatever style and way he/she leads the organization, the comparison between traditional leadership and e-leadership in this case may not be the main focus, in this case lies in how the character of a leader is able to achieve organization's goals to be better, although there are various characters and dimensions that must be met by organization leaders in today's digital era such as strong leadership will affect the success of achieving organization's goals, leaders who have a concrete vision and mission involve all people in the organization to carry it out, leaders who have commitment utilize and harmonize information technology to achieve organization's goals, and leaders who have a strong influence to control and manage the organization, , see also (Yudha \& Susanto, 2019). Besides, it is also important for e-leadership to motivate the employees to understand the performance of utilizing information technology, an e-leader must be able to establish various connections to communicate and build mutual trust, e-leadership and information technology are multidimensional spaces that will be able to contribute on the organization's performance if the organization's leaders can build trust in the diversity of the organization, (Savolainen \& López-Fresno, 2014), despite the lack of trust given to leaders, electronic governance of organizations becomes a strategy to provide more responsive services desired by the public,(Amita Singh, 2018). E-leadership as a new paradigm certainly has many challenges where almost all activities are carried out virtually and through computer mediation, where-leaders do not always face to face with employees in the organization and this is very influential on the organization's performance, (Al-Ghaili \& AlHarethi, 2019). However, for some organizations that already have supported information technology, it might be a competitive advantage, but what about other organizations such as small and medium enterprises? Absolutely, as a new paradigm, e-leadership in the perspective of small and medium enterprises is a skill that must be possessed by SME leaders in which they have to make various alignments between information technology and business operation models and sales, (Belitski \& Liversage, 2019) see also, (Ibrahim, Yaakob, \& Yusof, 2018). However, this transformation process requires a long time, see (Bruce J. Avolio, John J. Sosik, Surinder S. Kahai, 2014), especially in developing countries like Indonesia, although currently many e-commerce sites in Indonesia can be utilized by SME actors such as Tokopedia, Bukalapak, Shopee and many more. Furthermore, it can be emphasized that for large organizations, e-leadership may have become a culture to improve the organization's 
performance, but for small and medium organizations, e-leadership is a new knowledge that they must learn to build competitive advantage strategies with all its limitations so they must align according to the organization's needs.

\section{Method}

This study is conducted with a qualitative approach that aims to explore the challenges and opportunities of e-leadership to 20 informants consisting of 10 leaders of educational organizations and 10 leaders of SME who are willing to be interviewed by us virtually through video calls and Zoom. We do it this way because it is not possible to conduct direct and faceto-face interviews due to government policies to implement large-scale social restrictions in Indonesia, but this does not reduce the process of collecting data and information that we do despite some constraints such as time and internet networks that sometimes interfere with the interview process. Furthermore, interviews were conducted in an unstructured manner to be able to dig deeper data and have more flexibility when asking questions to informants, so that the questions given continue to develop and go deep to be able to provide a greater understanding of the research problems and questions. Interview recording was done automatically via video call or Zoom and documented in video format, the duration of the interview for each informant is on average 2 hours, we also re-interview if we get important data to explore.

\section{Result}

We have obtained interesting findings from this study in the form of challenges and opportunities possessed by the organization's leaders, especially in the aspects of education and small and medium enterprises that have influenced the performance of the organizations. In addition, we will also discuss how e-leadership from the perspective of educational organizations and small and medium enterprises and also the perspective of leadership from a gender aspect which will be discussed more broadly in the results and discussion. It has been discussed earlier that the COVID-19 pandemic has affected the culture of the organization, performance, and leadership in organizations. We have also found several new findings related to new challenges and opportunities about e-leadership in the context of the prevention of the 
spread of COVID-19 currently which are expected to be the basis for further studies to examine more deeply and broadly about the characteristics, dimensions, and theories of e-leadership.

\subsection{E-leadership Challenges:}

\subsubsection{Adaptation of Organization's Culture}

The culture of the organization as a character and characteristic of an organization certainly becomes a guideline for organizations to achieve its goals, but the current conditions force many organizations to abandon their guidelines for achieving goals with guidelines that can save their organizations in times of crisis today. However, many organizations must adapt to the new culture of the organization about how they manage the division of labor, customer management, and even leadership. In addition, adaptation and learning of organization are important factors for leaders to deal with all changes that will occur, give special attention to how to manage employees and manage the organization's wheels. Furthermore, leaders must have the skills to manage all this, even though the adaptation of the new culture of an organization takes time to increase work productivity or even has no effect on work productivity and almost all informants agree that they must adopt the culture of the organization even though they consider this is only temporary.

\subsubsection{Communication Skills}

Leaders certainly need communication skills. These skills are very useful when dealing with people both within the internal and external environment of the organization. For eleadership, the communication process will certainly require media such as computers and the internet either virtually or digitally, the communication processes will certainly be different from communication directly. Besides, by conducting virtual and digital communication, many informants state that it is very different, they feel a reduced level of trust compared to communicating directly where they can feel the response of the other person directly and the interaction occurs, the mutual respect that is seen directly, but they agree that communication skills are not only in the context of conventional communication (face to face without media) they need training in virtual and digital communication skills which will certainly have an 
impact on the effectiveness and efficiency of the performance of the organization and will impact on leaders who will learn independently related to communication skills.

\subsubsection{Social Media Ethics and Information Technology Skills.}

At present, communication mediation has many choices along with the development of technology and information, the organization's leaders have taken advantage of the advancement of this information technology for communication and coordination within the organization. However, communication through mediation in social media such as Facebook, Twitter, WhatsApp Messenger, Zoom Meeting must maintain the ethics and rules of communication that apply, communication through social media is certainly very different from direct communication where-leaders cannot be free in speaking because the conversation will certainly be seen by many people and has limited sentences in conveying the intent and purpose so that leaders are challenged to make effective communication in managing their organizations during the application of social distance and physical distance due to the COVID-19 pandemic. Besides communication skills, leaders in the digitalization era must also have skills in the use of information technology. Most of the leaders of small and medium enterprises, for example, state that they must learn a lot about applications supporting production and online sales because there are still many small and medium-sized businesses in Indonesia which have not yet maximized the role of technology and information such as e-commerce. Likewise for leaders in the field of educational organizations have instructed instructors to use information technology as a way to continue to carry out their duties and responsibilities, but still, the challenges they face are there are still teachers (teachers or lecturers) who do not understand the use of teaching and learning applications so a short course is required and that too must be carried out online to prevent the spread of COVID-19. Furthermore, the use of information technology in education will certainly help students and teachers continue to do learning where students can be encouraged to gain other competencies such as management skills, leadership, and motivation although emotional intelligence between students and teachers is the most important thing at present, the competencies needed in the digital age are e management, eleadership, and e motivation skills that must be balanced with emotional intelligence as their control function. Furthermore, there are interesting findings in small and medium business leaders where women leaders have more information technology skills than male leaders. This 
is because women leaders interact more often with information technology mediation such as gadgets, iPads, tablets, computers than male leaders so female leaders have more opportunities to learn independently about information technology and its use.

\subsubsection{Time Management}

Meanwhile, almost all leaders in the organizations state that they are very difficult in managing work time, this problem arises because in the "lockdown" condition set by the government who asks all organizations to employ their employees at home has forced the leaders of small and medium enterprises to take the decision to manage their organization by scheduling work systems (shifting) and sometimes employees are objected to the shifting system because they have to do new scheduling for personal matters. In addition, for leaders of educational organizations, they feel challenged to manage their work time when they have to reschedule routine work such as arranging teaching schedules for teachers, conducting performance evaluations and doing it with irregular time.

\subsubsection{Business Management Strategy}

Many small and medium business leaders in the current conditions have difficulty in determining their business management strategy, this is due to the limitation of economic and social activities that must be implemented so they must find new ways of managing their business such as goods delivery and ordering systems which, although it can be done online, consumers demand security and safety from the COVID-19 pandemic, so that small and medium-sized businesses leaders must think hard in determining new strategies for managing their business.

\subsubsection{Trust}

Leaders of educational organizations give the opinion that maintaining trust generally aims to maintain job satisfaction and productivity of teachers by motivating them and giving full rights of teachers even though the performance of the teacher or instructor is not optimal and shows managerial ability so that teachers and instructors feel that they are monitored and cared for by the leaders even though it is done through information technology mediation but 
for them, the meaning of the leader is as a flexible and complex human being from an information system so that they use the power to overcome the challenges of reduced trust from members of the organization.

\subsection{E-leadership Opportunities:}

\subsubsection{Social Learning and Knowledge Transfer}

Current environmental condition (the COVID-19 pandemic) positions leaders to deal with environments that they have never faced so they must learn from the others in dealing with and resolving the organization's problems through observation or ask more experienced persons so that they are able to implement their organization's management strategies and get a lot of experiences to be the solution to solve the problem. The leaders of the organization in the education sector exchange experiences about how to carry out the teaching and learning process between teachers and students while the small and medium business leaders share information and experiences about online sales and product packaging that can prevent the spread of COVID-19 to convince consumers. In addition, social learning has contributed to the knowledge of organization's leaders, they agree that as long as the social distance and region quarantine have provided opportunities for them to exchange information and knowledge of organizational leadership, they support each other to get out of this problem, they open up to each other to exchange information and knowledge so that the leaders of the organization have fully transformed into e-leadership and are very dependent on information technology so that the current organizational control is highly dependent on information technology skills and investment in information technology that they must do in the future.

\subsubsection{Flexibility}

Furthermore, the opportunity for leaders is the time flexibility that they get, they can manage the organization whenever and wherever, they can set the course of the organization following the agreement of all organization's members, although leaders have the power to determine their desires, all leaders agree that they generally determine working hours and ways of working and division of work following the agreement of all people in the organization. 


\subsubsection{Work-Life Balance}

All organization's leaders agree to state that when faced with this pandemic condition, they also get the opportunity to use quality time with family, they can work from home and control the organization while sharing family duties with their partners so that a balance between work life and social life is reached.

\section{Discussion}

The results of the study have been presented at the beginning and we have successfully explored the challenges and opportunities of e-leadership in the COVID-2019 pandemic. However, this COVID-19 outbreak clearly has had an impact on various aspects including the leadership style. E-leadership as one of the development of leadership theory has also been tested for its effectiveness by this condition and it has been proven by the organization's leaders who are part of this study where they reveal about the challenges and opportunities of eleadership during massive social restrictions and region quarantine determined by the Indonesian government so they are very dependent on information technology. Furthermore, the first challenge of e-leadership is that leaders must adopt the culture of the organization in a short time because they assume that the adaptation and learning of organizations to the threats that occur are very important for them to do to maintain the existence and performance of their organizations, and this has agreed with (Salehi, Mirsepasi, \& Farhangi, 2015) statement and see also, (Sabuhari, Sudiro, Irawanto, \& Rahayu, 2020). Second, communication skills are a challenge for e-leadership where they need to be more intensive in communicating through information technology mediation and, of course, this is different from communication when in normal conditions. They must improve their communication capabilities independently, especially for leaders of small and medium enterprises who have to change many communication methods with customers such as how to change delivery schedules, production schedules and also customer service due to restrictions on working hours and operating hours and this is a challenge for them to learn independently about how decision-making techniques they have to do. This also supports (Askari et al., 2018) statement. Third, the challenges of using social media and skills of using information technology both in education and small and medium businesses today, leaders are challenged to display their creativity by creating content 
using social media as a means of information, but once again they have limitations and also need more skills both in the use of information technology and ethics in utilizing social media, social media, and information technology will certainly help them solve problems and make decisions but they are also required to be more careful and prudent in its use so that they are also able to develop information technology skills directly and independent even though it is impressively forced by circumstances and this is agreed with (Marzuki, Mustaffa, \& Mat Saad, 2015). In addition, there are interesting findings from this challenge where female leaders are superior to male leaders both in ethics and skills of information technology, this is because women tend to be more careful in delivering messages through social media and they are more often and more time in studying gadgets and technological devices compared to male leaders. Fourth, however, time management is one of the best skills that must be possessed by eleadership, see (Znaidi \& Sabir, 2019). Furthermore, with good time management and a combination of information technology, organization's leaders will successfully overcome this challenge and will become leaders who have character and can manage their organizations without time and place constraints, this supports(Wiam Wahab Abdel-Hussein, 2020). Fifth, leaders must change their business strategy during the pandemic, management of this business management strategy will certainly require development and new skills for leaders and employees, and this has supported (Postavaru, Draghici, Filip, Mohammed, \& Mohammed, 2020) statement. Trust is an important dimension for leaders of the organization, this also applies to e-leadership where trust is something that must be guaranteed and shown to the public. By doing work online, leaders of both educational organizations and small and mediumsized businesses state that maintaining trust is a formidable challenge where they have an important role to develop trust that is correlated with how they are able to influence the people around them, both employees and consumers. In addition, they also have to make a joint agreement even though it is sometimes not a demand from consumers but they do to maintain the trust of consumers. However, as humans, they are complex and have more responsibilities than information technology in the context of trust and this is discussed in (DeRosa, Hantula, Kock, \& D’Arcy, 2004) see also, .

Furthermore, the opportunity for e-leadership in the first pandemic is social learning that emphasizes on how environments are confronted by a person by chance and that environment is selected and modified by them according to their behavior and needs, as 
conveyed by (Bandura, 1986) that most people learn through selective observation and remember the behavior of others and then they can imitate the behavior if it is in accordance with the behavior and goals to be achieved. Furthermore, with social learning, leaders get new experiences from people who first solve problems in their way and is a transfer of knowledge that is very useful for them to develop strategies in the future when faced with threats that might happen again. The second opportunity is that they get the flexibility that gives authority to regulate and control the organization following the wishes of the leader and also members of the organization and this can reduce conflict in the organization because the opportunity to create harmony among members of the organization is very huge. And the third is the opportunity for leaders to achieve work-life balance is huge if they are able to practice eleadership and able to overcome all the challenges they face. In addition, by working from home, they also avoid the distractions they usually get in the office such as noise, crowds and other disturbances, by working from home they feel more comfortable and have more flexible work areas so that supervision and organizational control can be done simultaneously with responsibility for his family's duties, this supports the (Dockery \& Bawa, 2018) findings and also (Cantera, Cubells, Martínez, \& Blanch, 2009).

\section{Conclusion}

This article has successfully explored challenges and opportunities for e-leadership during the COVID-19 pandemic conditions and has discussed the previous findings. However, we have limitations in conducting studies with current conditions where social restrictions and region quarantine make it difficult for us to conduct direct interviews and observations on informants, but this study has contributed to studies that focus on e-leadership where we have successfully explored e-leadership challenges and opportunity during the COVID-19 pandemic that make organization's leaders switch their leadership style to e-leadership and this proves that e-leadership can be created if leaders can overcome all challenges and will get great opportunities to build competitive advantage strategies for their organizations. We have also opened up opportunities for further studies to conduct deeper studies related to the e-leadership challenges and opportunities which might be more findings if conducted under normal conditions without restrictions and region quarantine. 


\section{References}

Al-Ghaili, M. A. A., \& Al-Harethi, A. A. M. (2019). Managers' Readiness To Adopt ELeadership. International Journal of Research, 6(10), 845-874. Retrieved from https://184.154.194.75/index.php/ijr/article/view/19438

Amita Singh. (2018). e-Governance and Ethical Leadership. Retrieved from https://www.researchgate.net/publication/320441703

Askari, R., Rafiei, S., Montazerolfaraj, R., Fallahzadeh, H., Keyghobadi, N., \& Dashtabadi, M. (2018). Role of managers' communication skills and leadership style on organizational effectiveness: Path analysis. The Journal of Qazvin University of Medical Sciences, 21(6), 63-55. https://doi.org/10.29252/qums.21.6.63

Bandura, A. (1986). Social foundations of thought and action: A cognitive social theory. New York: Pretince Hall.

Belitski, M., \& Liversage, B. (2019). E-Leadership in Small and Medium-Sized Enterprises in the Developing World. Technology Innovation Management Review, 9(1), 64-74. https://doi.org/10.22215/timreview/1212

Bruce J. Avolio, John J. Sosik, Surinder S. Kahai, B. B. (2014). E-leadership: Re-examining transformations in leadership source and transmission. The Leadership Quarterly, 25(1), 105-131. https://doi.org/https://doi.org/10.1016/j.leaqua.2013.11.003

Cantera, L. M., Cubells, M. E., Martínez, L. M., \& Blanch, J. M. (2009). Work, family, and gender: Elements for a theory of work-family balance. Spanish Journal of Psychology, 12(2), 641-647. https://doi.org/10.1017/S1138741600002006

Capogna, S., Figus, A., \& Mustica, S. (2018). The Challenges for Digital Society: Education and E-Leadership. International Journal of Innovation and Economic Development, 4(3), 12-19. https://doi.org/10.18775/ijied.1849-7551-7020.2015.43.2002

Cruz, B. S. (2020). COVID-19: FROM OUTBREAK TO PANDEMIC. Global Scientific Journals, 8(3), 2230-2238. Retrieved from www.globalscientificjournal.com\%0A

DeRosa, D. M., Hantula, D. A., Kock, N., \& D’Arcy, J. (2004). Trust and leadership in virtual teamwork: A media naturalness perspective. Human Resource Management, 43(2-3), 219-232. https://doi.org/10.1002/hrm.20016

Dockery, A. M., \& Bawa, S. (2018). When two worlds collude: Working from home and family functioning in Australia. International Labour Review, 157(4), 609-630. 
https://doi.org/10.1111/ilr.12119

Ibrahim, M. Y., Yaakob, M. F. M., \& Yusof, M. R. (2018). The effect of e-leadership and team communication on well-being of school leaders in Malaysia. International Journal of Civil Engineering and Technology, 9(7), 994-999.

Marzuki, N. A., Mustaffa, C. S., \& Mat Saad, Z. (2015). Emotional intelligence: Its relationship with communication and information technology skills. Asian Social Science, 11(15), 267-274. https://doi.org/10.5539/ass.v11n15p267

McKibben, W., \& Fernando, R. (2020). Centre for Applied Macroeconomic Analysis The Global Macroeconomic Impacts of COVID-19: Seven Scenarios. 1-45.

Oh, S. P., \& Chua, Y. P. (2018). An Explorative Review of E-Leadership Studies. International Online Journal of Educational Leadership, 2(1), 4-20. https://doi.org/10.22452/iojel.vol2no1.2

Postavaru, N., Draghici, G., Filip, C., Mohammed, A.-R., \& Mohammed, S. M. (2020). Business Management Strategies for Business Development. Organization of the Territory and Planning of Construction Works. Ovidius University Annals of Constanta - Series Civil Engineering, 21(1), 45-50. https://doi.org/10.2478/ouacsce-2019-0005

Rey-Martí, A., Ribeiro-Soriano, D., \& Sánchez-García, J. L. (2016). Giving back to society: Job creation through social entrepreneurship. Journal of Business Research, 69(6), 2067-2072. https://doi.org/10.1016/j.jbusres.2015.12.010

Rodela, T. T., Tasnim, S., Mazumber, H., \& Faizah, F. (2020). Economic Impacts of Coronavirus Disease ( COVID-19) in Developing Countries. Retrieved from https://www.researchgate.net/publication/340438009

Sabuhari, R., Sudiro, A., Irawanto, D. W., \& Rahayu, M. (2020). The effects of human resource flexibility, employee competency, organizational culture adaptation and job satisfaction on employee performance. Management Science Letters, 10(8), 1777-1786. https://doi.org/10.5267/j.msl.2020.1.001

Salehi, S. M. R., Mirsepasi, N., \& Farhangi, A. A. (2015). Investigating organizational culture adaptability of broadcasting firm in response to environmental changes. Management Science Letters, 5, 975-978. https://doi.org/10.5267/j.ms1.2015.10.002

Savolainen, T., \& López-Fresno, P. (2014). Trust in Leadership for Sustaining Innovations: How Leaders Enact on Showing Trustworthiness. Nang Yan Business Journal, 1(1), 
129-136. https://doi.org/10.2478/nybj-2014-0018

Van Wart, M., Roman, A., Wang, X. H., \& Liu, C. (2019). Operationalizing the definition of e-leadership: identifying the elements of e-leadership. International Review of Administrative Sciences, 85(1), 80-97. https://doi.org/10.1177/0020852316681446

Wiam Wahab Abdel-Hussein. (2020). The impact of time management on the success of service organizations. Technium Social Sciences Journal, 5, 249-255.

Yudha, H., \& Susanto, T. D. (2019). E-Leadership: The Effect of E-Government Success in Indonesia. Journal of Physics: Conference Series, 1201(1). https://doi.org/10.1088/1742-6596/1201/1/012025

Znaidi, K., \& Sabir, A. (2019). How Good Is Your Time Management. Budapest International Research and Critics Institute (BIRCI-Journal) : Humanities and Social Sciences, 2(4), 682-697. https://doi.org/10.33258/birci.v2i4.686 